\title{
Working
}

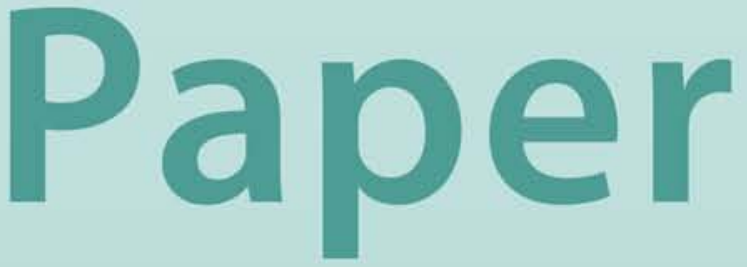




\section{Beauty Queens and Wallflowers- Currency Maps in the Middle East and Central Asia}

Julian Berengaut and Katrin Elborgh-Woytek 


\title{
IMF Working Paper
}

Middle East and Central Asia Department

\section{Beauty Queens and Wallflowers- Currency Maps in the Middle East and Central Asia}

\author{
Prepared by Julian Berengaut and Katrin Elborgh-Woytek ${ }^{1}$
}

October 2006

\begin{abstract}
This Working Paper should not be reported as representing the views of the IMF. The views expressed in this Working Paper are those of the author(s) and do not necessarily represent those of the IMF or IMF policy. Working Papers describe research in progress by the author(s) and are published to elicit comments and to further debate.
\end{abstract}

Against the background of the theory of optimum currency areas, the paper analyzes possible sequences for establishing a currency union (CU) in the Middle East and Central Asia region. Between the corner solutions of independent currencies for all countries in the region and a CU comprising all countries, a large number of combinations of member countries in the CU is possible. The analysis aims to determine the composition of potential CUs as a function of the country initiating the $\mathrm{CU}$, an exogenously determined number of currencies in the region, and the weight attached to the particular selection criteria. Within this framework, the study seeks to establish whether some countries are consistently selected at early stages of the process, while others join only at later stages.

JEL Classification Numbers: F33, F36, N15

Keywords: Currency Union, Optimum Currency Areas, Middle East, Central Asia

Authors’ E-Mail Addresses: jberengaut@imf.org; kelborghwoytek@imf.org

\footnotetext{
${ }^{1}$ We wish to thank Mohsin S. Khan and other participants in an IMF Middle East and Central Asia Department (MCD) seminar for valuable comments. Helpful comments were also provided by Elvira Eurlings. Thanks are due to David Velazquez and Saeed Mahyoub for their excellent research assistance, and to Maria Llames and the IMF Graphics Section for outstanding project support.
} 


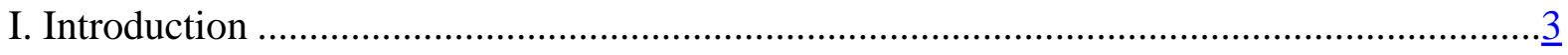

II. The Theory of Optimum Currency Areas ...................................................................

III. Assumptions and Methodology …........................................................................... 7

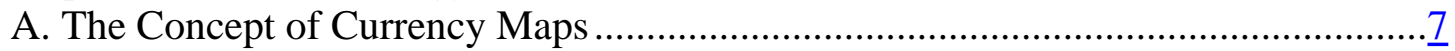

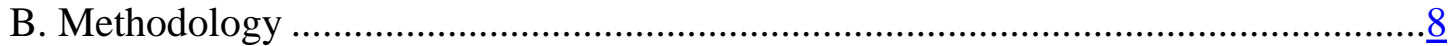

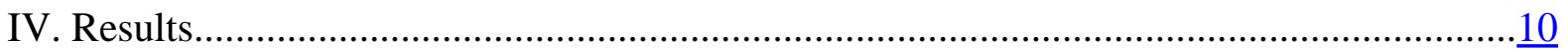

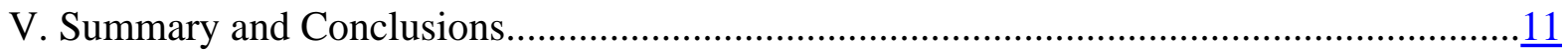

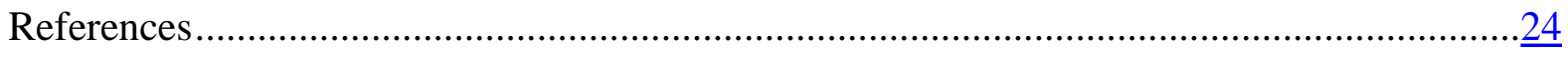

\section{Tables}

1. Currency Maps: MCD Preferred Country Ranking .....................................................13

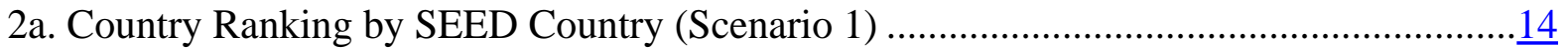

2b. Country Ranking by SEED Country (Scenario 2) ....................................................16

2c. Country Ranking by SEED Country (Scenario 3) …..................................................18

Figures

1. Pakistan (SEED): Currency Maps ....................................................................... 20

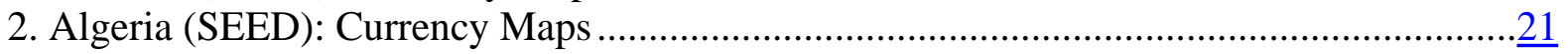

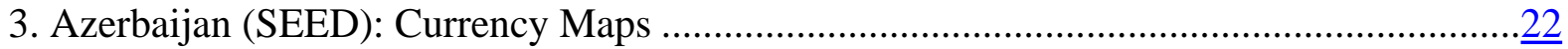

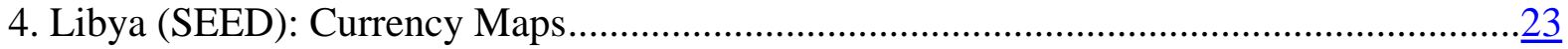




\section{INTRODUCTION}

A large number of countries have become members of currency unions (CUs), ${ }^{2}$ with the aim of improving their economic performance. Regional examples include the European Economic and Monetary Union (EMU), the East Caribbean Currency Area, and the CFA Franc Zone in West Africa. However, in the Middle East and North Africa (MENA) region, no CUs have been established as yet. The Gulf Cooperation Council (GCC) remains the forum for the closest formal economic cooperation, possibly leading to a monetary unionalbeit not before 2010. The economies of Central Asia, having emerged only recently from the enforced single-currency area of the Soviet ruble zone, maintain independent currencies.

Recently, the most conspicuous example of a newly established vibrant CU has been the euro area. Unlike some other CUs that had been set out from scratch (e.g., the African arrangements), the euro area CU grew organically over time-from a small nucleus to a much larger combination of countries. The accession process for new members of the euro zone has been notable for two reasons: (a) accession countries were generally geographically proximate; and (b) candidate countries had to demonstrate, prior to accession, that they would be able to perform inside the CU, implying that they had become, in their structure and performance, sufficiently similar to the union insiders. These two broad features of the selection process for new members are emphasized in this paper.

Our paper aims to analyze possible sequences for establishing and expanding CUs in the Middle East and Central Asia (MCD) region. Between the corner solutions of independent currencies for all countries in the region and a CU comprising all countries, a large number of combinations of CU members is possible. The analysis aims to determine the composition of potential CUs as a function of initial conditions - the country initiating the CU-and of the exogenously determined number of currencies in the region. Within this framework, we are able to establish, irrespective of the starting point of the exercise, which countries would constitute the most likely members of the CU. We dub these countries "beauty queens." At the other extreme, irrespective of the initial conditions, we determine which countries would only be selected in the final stages. We dub these countries "wallflowers." In addition to providing background to possible monetary integration in the region, the paper provides insights with regard to the nature of economic links among MCD countries, the scope for regional trade, and the potential for transmission of shocks across the region.

Section II outlines the theory of optimum currency areas and provides an overview of recent empirical findings on the benefits and cost of membership. Section III discusses the assumptions and methodology underlying the sequenced aggregation of countries in hypothetical CUs in the MCD region. As a starting point, the concept of a currency map is presented; based on particular selection criteria, a currency map is defined as the graphical

\footnotetext{
${ }^{2}$ The term "currency union" denotes a number of sovereign countries that adopt a single currency, issued by a joint central bank, as opposed to a "monetary union" characterized by the coexistence of national currencies (IMF, 2006).
} 
representation depicting the countries constituting the CU, subject to the twin constraints of the initial conditions and the exogenously determined number of currencies in the region. Starting from the theory of optimum currency areas, the methodological approach used in this section to operationalize the sequencing of countries draws heavily on gravity models. The outcomes for selected CU sequences and the resulting ranking of MCD countries are presented in Section IV. Section V summarizes the findings and offers suggestions for further research.

\section{The Theory OF Optimum CURRENCY AREAS}

The concept of optimum currency areas (OCAs) was initially developed in the early 1960s, with a focus on defining the preconditions for successful CUs. In his pioneering contribution, Mundell (1961) emphasized factor mobility, in particular labor mobility, as a key prerequisite for participation in a CU. McKinnon (1963) identified openness as the main criterion, implying that small, open economies that were more exposed to exchange rate fluctuation would benefit the most from a CU with a large and stable trading partner. Kenen (1969) stressed the degree of an economy's diversification, as more diversified economies are less exposed to shocks, and therefore less likely to face the disadvantages of sacrificing the exchange rate instrument. Since its initial phase, the theory of optimum currency areas has evolved considerably, with more recent research focusing on the costs and benefits of CUs, and on the analysis — in a variety of frameworks — of the consequences of sacrificing exchange rate autonomy. ${ }^{3}$ The renewed interest in OCAs in the 1990s was motivated by European monetary integration, as well as by protracted currency crises in emerging market economies.

On the benefit side, the implications of joining a CU are manifold. Per capita GDP growth in members of CUs has been found to be higher than in comparable countries (Edwards and Magendzo, 2002), as a result of improved efficiency of resource allocation and increased access to product, factor, and financial markets, which facilitate investment. Higher growth could also be the result of reduced transaction costs because nominal exchange rate uncertainty is eliminated and real exchange rate uncertainty is reduced (Bottazzi and Manasse, 2002). At the same time, inflation in members of CUs has been found to be lower than in a control group of countries with their own currency (Edwards and Magendzo, 2002). However, while CUs may lead to a reduction in interest rates as a result of a lower currency risk premium, the risk of high interest rates resulting from expectations of high inflation in some member countries of the CU remains. Business cycles were found to be more highly correlated between members of CUs than between countries with sovereign currencies (Persson, 2001).

\footnotetext{
${ }^{3}$ The original concepts were formalized in general-equilibrium models by Bayoumi (1994) and Ricci (1997), among others.
} 
Although most authors acknowledge the trade intensity-enhancing effect of CUs as exchange rate volatility and transaction costs are reduced, its magnitude has been the subject of debate. The analysis conducted by Rose and Stanley (2005) points to a robust, positive effect of CU membership on trade on the order of a 30 percent to 90 percent increase. Based on gravity modeling, Rose and Engel (2002) demonstrate a trade-enhancing effect of a factor of over 3 compared to countries that do not form part of a CU, while not finding evidence of trade diversion. Glick and Rose (2002) posit that bilateral trade rises by about 100 percent as a pair of countries forms a CU, ceteris paribus. CUs are found to be equally beneficial to bilateral trade in large countries as in small ones. ${ }^{4}$ Micco, Stein, and Ordoñez (2002) estimate that the establishment of the EMU resulted in an increase in trade between 12 percent and 19 percent. Adjusting the data set and regression specification used by Rose and Engel (2002), Nitsch (2002) reduces the trade-enhancing effect of a common currency from a factor of about 3 to 2.5, nevertheless demonstrating a substantial impact of CU membership on trade. ${ }^{5}$ However, Persson (2001) posits that estimates of substantial trade-enhancing effects could reflect nonlinearities, as well as systematic, unaccounted-for selection into common currencies of country pairs with peculiar characteristics. Baxter and Kouparitsas (2006) also cast doubt on the hypothesis that membership in a CU plays an independent role in determining bilateral trade, arguing that the CU variable used in some studies is not robust to the inclusion of other variables.

The formation of CUs can give rise to significant costs as policymakers forfeit the ability to use national monetary policy to respond to shocks. Accordingly, in evaluating the feasibility of a CU, both the nature of potential shocks and the speed with which member countries adapt to them are critical. ${ }^{6}$ A loss of sovereignty over monetary and exchange rate policies also implies loss of the ability to influence the inflation rate. The potential loss of seigniorage (as only a predefined share of seigniorage would accrue to each member of a CU) could add to the costs. However, costs can be minimized by greater wage and price flexibility, and economies' ability to adapt to shocks through factor mobility. In view of the loss of monetary instruments to reduce real shocks, the key role in smoothing the impact of idiosyncratic exogenous shocks would need to be assumed by fiscal policy (Ferrero, 2005; Kirsanova, Vines; and Wren-Lewis, 2006).

\footnotetext{
${ }^{4}$ However, with the exception of EMU, there have not been any CUs in the modern era involving large, prosperous countries. If CUs among the latter were to have different effects than CUs among small or poor countries, historical data would not demonstrate this (Frankel and Rose, 2002).

${ }^{5}$ The paper mentions, though, that it is possible to find a specification in which the effect of CUs on trade is essentially zero, suggesting that "projections about the potential trade-enhancing effect of adopting a common currency are, at best, extremely unreliable” (Nitsch, 2002).

${ }^{6}$ Ca’Zorzi, de Santis, and Zampolli (2005) note that structural change in one or more member countries of a CU could entail supply and real exchange rate shocks for the rest of the area.
} 
With regard to the question of which countries should associate themselves in forming a CU, Yehoue (2004) emphasizes that currency bloc formation is path dependent, with each additional member serving in a dynamic way to attract more members to the bloc. As countries tend to trade more with large neighbors, the benefits of adopting the currency of a large neighbor would exceed the benefits of adopting the currency of a smaller or more distant country. A small country with a history of high inflation would have particular incentives to give up its own currency in favor of that of a large and - from a monetary point of view-stable country, as credibility can be established when the central bank "ties its hands" with a rigid institutional commitment to monetary stability (Alesina and Barro, 2002; Bottazzi and Manasse, 2002). The establishment of a CU could also be motivated by the aim to counteract perceived economic and political weakness (Masson and Pattillo, 2004).

Empirical analyses of currency and monetary unions abound. With regard to the potential costs and benefits of adopting the euro in Central and Eastern Europe, Nuti (2002) finds that net effects would depend on the degree of monetary, real, and institutional convergence. Chernookiy (2005) emphasizes the asymmetric character of the envisaged CU between Russia and Belarus. For a limited Latin American data set, Edwards (2006) finds that the (negative) effects of external crises on GDP growth have tended to be more severe in CU members than in countries maintaining flexible exchange rates. Sánchez (2005) assesses the prospects for a CU among emerging East Asian economies.

Based on the historical patterns of intra-Africa trade and co-movements of prices and outputs, Yehoue (2005) finds limited normative support for establishing a single African currency (as envisaged by the African Union), but sees a possibility for three separate currency blocs in West Africa, South Africa, and Central Africa, respectively, with the remaining sub-Saharan African countries keeping their respective currencies. On a similar note, in their analysis of the Economic Community of West African States (ECOWAS), Tsangarides and Qureshi (2006) underline the considerable divergence in member countries' exposure to exogenous shocks. Debrun, Masson, and Pattillo (2002) find that the proposed monetary union among all ECOWAS members would not be incentive-compatible for most existing West African Economic and Monetary Union (WAEMU) members in the absence of major institutional changes, as possible fiscal distortion in Nigeria could result in potential pressure on the union's central bank to produce excessive inflation. Masson and Pattillo (2004) show that a single currency in Africa would entail gains only for ECOWAS and the Common Market for Eastern and Southern Africa (COMESA), regions with substantial financing needs in proportion to GDP, while regions with more disciplined fiscal policies (Arab Maghreb Union, Southern African Development Community, and Economic Community of Central African States) would not gain (see also Masson and Patillo, 2005). The authors also find that the experiences of Africa's two main monetary or formal exchange rate unions - the CFA franc zone and the Common Monetary Area based on the South African rand-do not suggest a significant increase in regional trade. African countries with a common currency have so far not been successful with regard to price stability and optimal monetary policy changes in response to various asymmetric shocks. However, the CFA franc zone was found to have enjoyed lower inflation than other currency regimes in Africa. 
With respect to CUs among the GCC countries, Laabas and Liman (2002) find that political preconditions are stronger than economic prerequisites, as intra-regional trade, convergence in main macroeconomic fundamentals, and synchronization of business cycles are limited. While the GCC countries share high openness ratios, factor mobility, price and wage flexibility, and commodity diversification remain low. Although inflation has been brought down to the single digits, evidence of correlation between inflation rates is scant.

Analyses of CUs are hampered by endogeneity problems as countries become similar when they share a common currency (Frankel and Rose, 1996; Tsangarides and Quereshi, 2006). Frankel and Rose (2000) caution that the decision to form a CU could be endogenous as historical, political, and cultural links tend to promote bilateral trade, and that either these links or the bilateral trade could give rise to the decision to adopt a joint currency. Obviously, countries are more likely to satisfy the criteria for entry into a CU ex post, after taking steps toward economic integration, than ex ante (Frankel and Rose, 1996). On a related note, analyzing the conditions for joining a CU not only ex ante, but also ex post, Alesina, Barro, and Tenreyro (2002) find that the trade patterns and co-movements that applied before the adoption of a common currency would underestimate the potential benefits from joining a CU.

\section{Assumptions AND Methodology}

\section{A. The Concept of Currency Maps}

This paper analyzes the possible sequencing of establishing a CU in the MCD region. The corner solutions are defined as, on the one hand, independent currencies for all countries in the region and, on the other hand, a CU comprising all countries. In between, a substantial number of combinations of CU members is feasible. Our analysis determines the composition of potential CUs as a function of the country initiating the $\mathrm{CU}$ and of the exogenously determined number of currencies in the region.

For illustrative purposes, currency maps are defined as the graphical representation depicting the countries constituting the CU, subject to the constraints set out above. The concept implies that, starting with a selected country, a sequence of preferred partner countries in a joint currency area can be identified. ${ }^{7}$ The currency map depicts the common currency area at a given stage of the sequence. To make the analysis tractable, we assume that at any point in the sequence, only one $\mathrm{CU}$ exists in the region. The graphical presentation of $\mathrm{CU}$ sequences aims to answer the following questions:

\footnotetext{
${ }^{7}$ Fryer and Torelli (2005) use a similar methodology in determining the popularity of students by identifying friendship networks.
} 
- Which currency map corresponds to an exogenously determined number of currencies in the region?

- $\quad$ How contingent is the currency map on the country initiating the CU?

- $\quad$ Are there any countries in the region that are consistently selected in early stages (beauty queens) or in later stages (wallflowers).

\section{B. Methodology}

Our procedure allows any of the $27 \mathrm{MCD}$ countries $^{8}$ to be selected as the starting point for the exercise. Beginning with a given seed country (which we call SEED), we calculate the ordinal ranking of the remaining countries to find the preferred candidate (PC) - from the perspective of the SEED - for joining a CU. By combining these two countries, a new virtual country (VC) is established, which in turn could serve as a new SEED. We continue the exercise until all 27 MCD countries have joined the CU.

In order to identify the PC at any stage of the process, we calculate ordinal rankings between the SEED and all remaining MCD countries that have not yet been integrated into the CU, based on five criteria. Of these, two attempt to capture potential gains from trade based on standard gravity modeling, while the remaining three measure the scope for asymmetric shocks, so as to gauge the costs of losing monetary independence.

- $\quad$ Distance: The shorter the distance between the SEED and a given country, the higher its ranking. We use distances between capitals, and, for virtual countries, the average of distances between the component countries and third countries. ${ }^{9}$

Define $D(u, k)$ as distance between capitals of countries u and k; with 27 countries in MCD, assume that SEED comprises $p$ countries with $p$ bounded between 1 and $25{ }^{10}$

Thus, we calculate:

$$
\begin{array}{ll}
\sum_{i, j} D(i, j) / P & \text { first for }(i=1, \ldots p) \text { to average the distances and then for } \\
& j=(p+1, \ldots, 25) \text { to establish the ranking }
\end{array}
$$

\footnotetext{
${ }^{8}$ The analysis omits Afghanistan, Djibouti, Iraq, Somalia, and West Bank and Gaza because of difficulties in data compilation. For all other countries, IMF Board documents for 2003 and 2004 and IMF country desks constitute the main data sources.

${ }^{9}$ The distance data were taken from $\underline{w w w . w c r l . a r s . u s d a . g o v / c e c / j a v a / c a p i t a l s . h t m}$.

${ }^{10}$ Obviously, no calculation is necessary to select the last remaining country.
} 
- $\quad$ Output: The larger the non-oil GDP of a given country (as of 2003), the higher its ranking relative to the given SEED. The oil economy is excluded as frequent price fluctuations distort the data and because we assume that all oil is already traded without much scope for additional trade. To construct virtual countries, we sum nonoil GDPs of the constituent countries.

- $\quad$ Output fluctuation: The greater the similarity of the growth rates between the SEED and a given country, the higher its ranking. We use simple correlation of growth rates over the period 1998-2003.

Defining $Q(n, k)$ as the similarity index for growth rates between countries $n$ and $k$, we calculate it as:

$$
Q(n, k)=\operatorname{corr}\left(g_{n}^{i}, g_{k}^{i}\right) \quad \text { for } i=1998, \ldots, 2003
$$

For virtual countries, the growth rate of output equals the GDP-weighted average of the growth rates of outputs of the component countries. Thus, the growth rate of a virtual country comprising $p$ countries is

$$
g_{v c}=\sum_{i}\left[g_{i}\left(\frac{G D P_{i}}{\sum_{i} G D P}\right)\right] \quad \text { for } i=1, \ldots, p
$$

- $\quad$ Trade structure: The greater the similarity between the export structures of the SEED and a given country, the higher its ranking. Export structures refer to shares of exports (in U.S. dollars for 2003, or latest available), accounted for by services, energy, ${ }^{11}$ other raw materials, agricultural and food items, industrial goods, and other items (six categories in total). Thus, let export shares $\alpha$ in country $n$ exports be $\alpha_{i}^{n}$ for $i=1, \ldots 6$ and let export shares in country $k$ exports be $\alpha_{i}^{k}$ for $\mathrm{i}=1, \ldots, 6$.

The index is calculated as:

$$
E(n, k)=\operatorname{corr}\left(\alpha_{i}^{n}, \alpha_{i}^{k}\right) \quad \text { for } i=1, \ldots, p
$$

In the case of virtual countries, the structure of exports of the combined country is equivalent to the GDP-weighted average of structures of the component countries.

\footnotetext{
${ }^{11}$ While the oil economy is excluded from GDP calculations, energy exports have been included in this calculation in order to capture the synchronicity of shocks (rather than the trade potential).
} 


$$
\alpha_{v c}=\sum_{i}\left[\alpha_{i}\left(\frac{G D P_{i}}{\sum_{i} G D P}\right)\right] \quad \text { for } i=1, \ldots, p
$$

- Inflation performance: The similarity of inflation performances is critical for minimizing asymmetric shocks. For virtual countries, the inflation rate is the GDPweighted average of the inflation rates of component countries. The index is based on calculating the inflation differential for 2003 and assigning the highest score to the lowest differential. Positive differentials (i.e., countries within the CU having a higher inflation rate than countries outside the $\mathrm{CU}$ ) would be given preference over negative differentials. $^{12}$

To obtain an aggregate ranking between a SEED and the remaining non-CU countries, we simply add up the rankings based on the five criteria set out above. Simulations of CU sequencing were carried out with three different sets of weights. In the baseline scenario, we assigned equal weights of 0.2 to each of the five variables. In an alternative scenario, we assigned greater weight to the variables representing the potential for asymmetric shocks. While the two gravity model-based variables, distance and size of GDP, were assigned a weight of 0.1 , the remaining three variables received a weight of 0.267 . In an additional scenario, we increased the weights of the variables distance and size of GDP to 0.25 , while the other three variables were assigned a weight of 0.167 . The results of the three scenarios are presented in the following section.

\section{RESUlts}

Using the three sets of weights, we simulated the sequences for establishing CUs for all 27 countries in the MCD region. Table 1 shows the average preferred country ranking for three scenarios with different weights for the five criteria. Samples of the resulting currency maps for the baseline scenario are presented on the following pages. For illustrative purposes, we show potential CUs with 3, 5, 10, and 15 member countries with Pakistan, Algeria, Azerbaijan, and Libya as starting points (Figures 1-4). As shown in the figures, the sequences for Pakistan and Algeria on the one hand, and the ones for Azerbaijan and Libya on the other hand, are strikingly similar, despite obvious differences between these countries. ${ }^{13}$ To facilitate the analysis, we also calculated the average ranking of all potential partner countries, with a low numerical score indicating high attractiveness of a country. The complete lists of preferred partner countries for the respective 27 SEEDs and the three scenarios are presented in Tables 2 a-c.

\footnotetext{
${ }^{12}$ For illustrative purposes, this implies that for a hypothetical country $\mathrm{G}$ with an inflation rate of 6 percent and potential partner countries with inflation rates of 4 percent, 5 percent, 7 percent, and 8 percent, the ranking would be the highest for the country with an inflation rate of 5 percent, followed by those with rates of 4 percent, 7 percent, and 8 percent.

${ }^{13}$ PowerPoint-based simulations of CU sequencing for all 27 countries are available from the authors.
} 
The results demonstrate that, regardless of where CUs start, some countries are consistently favored as CU partners, while others are consistently seen as less attractive. As shown by the lists of preferred countries, currency maps are robust with respect to the initial conditions, and with respect to changes in the criteria weights. ${ }^{14}$

All three lists of average rankings are topped by Saudi Arabia and Kuwait, with other GCC countries being close followers. Azerbaijan, Algeria, and Pakistan are listed among the top ten in all three scenarios, as is Iran in the two scenarios giving a relatively low weight to inflation. ${ }^{15}$ At the other extreme, Mauritania, Uzbekistan, and Tajikistan constitute the lower end of all three ranking lists. Armenia, Georgia, Jordan, and Yemen remain among the ten countries with the highest averages (lowest attractiveness), irrespective of variable weights. With some iterations, the midfield also remains relatively stable. The ranking list for the second scenario, with a lower weight for gravity model-related variables, is somewhat more compressed than those for the other two scenarios. Interestingly, preferences for partner countries cut across the distinction between the former Soviet Union and the MENA region.

\section{SUMMARY AND CONCLUSIONS}

Country authorities see deeper economic integration as generally beneficial to raising their countries' growth potential because it allows them to take advantage of the international division of labor. Equally, macroeconomic stability has been broadly accepted as a prerequisite to sustained growth. Decision makers thus face the task of choosing the monetary and exchange rate arrangements that would be most supportive of economic integration and macroeconomic stability. In this context, CUs have proven to be durable choices for countries across the entire spectrum of economic development.

The question addressed in this paper is what the process of establishing CUs among MCD countries might look like. Obviously, one is not in the position to predict the future. But if countries decided in favor of joining CUs, and if the process of expanding such unions was to follow a process akin to the expansion of the euro area, then it is possible to present hypothetical MCD CU sequences and examine their commonalities, as well as their differences.

The basic concept employed in this paper is that of a currency map-a geographical representation of a CU subject to the constraints of the initial condition (i.e., the country originating the sequence) and the number of currencies in the region. The path to a given currency map is governed by five criteria: two proxying possible gains from trade based on

\footnotetext{
${ }^{14}$ The robustness of the results is further confirmed by an additional scenario, which introduced movements in the real exchange rate as a proxy for the synchronicity of shocks, with weights of 0.25 for distance, 0.25 for non-oil GDP, and 0.50 for real exchange rate movements. The results were very similar.

${ }^{15}$ As Iran's inflation rate tops the MCD region, the country becomes less attractive as a CU partner, once a higher weight is assigned to the inflation variable.
} 
gravity models, and three proxying structure and performance similarities. Countries successively select partners for membership in their CU based on these five criteria until all the countries of the region join in. Our framework allows us to vary the weights that are attached to the five criteria.

The surprising finding of the study is that, in the MCD region, there is a group of countrieswhich we dub beauty queens - that are consistently selected at the early stages of the sequences, and the choice of these countries is broadly robust with respect to the starting point of the sequence and the weights assigned to the selection criteria. These beauty queens are Saudi Arabia and some other GCC countries. However, there is also another group of countries that are consistently selected at the final stages of the sequencing, and this choice of countries is also robust with respect to the starting point and the criteria weights. The members of this group — which we dub wallflowers — are Mauritania, Uzbekistan, Tajikistan, and Yemen.

The choice of a country's monetary and exchange rate regime is almost always based on a combination of political and economic factors. Efforts to engage in regional integration are driven by the same combination of factors. In discussing these policy options, it would seem advantageous to develop a simple methodology that would allow us to simulate the process of CU expansion based on economic criteria, albeit criteria that mimic the selection process that has governed the expansion of the euro area. Against the backdrop of various attempts to foster regional integration, the identification of early and late candidate countries provides us with insights for assessing these processes.

The scope for further research is considerable. The framework could be applied to other regions to see whether the central finding of identifying robust groupings of beauty queens and wallflower countries could be duplicated. At the same time, the framework could be expanded to handle additional criteria (e.g., financial variables such as interest rates; countries' debt-to-GDP ratios; and primary fiscal deficits). Another area of interest is the possible presence of nonlinearities. Perhaps distance does not matter very much up to a certain level but has a significant impact on anything above the threshold. Perhaps small differences in structure or performance are ignored by economic decision makers but differences beyond a certain threshold are seen as prohibitive. Thus, among the questions that could be addressed in an expanded framework, the robustness of the sequences to the introduction of various nonlinearities could also be examined. 
Table 1. Currency Maps: MCD Preferred Country Ranking (Averages)

\begin{tabular}{|c|c|c|c|c|c|}
\hline Scenario 1 & & Scenario 2 & & Scenario 3 & \\
\hline Saudi Arabia & 2.8 & Saudi Arabia & 4.2 & Saudi Arabia & 2.7 \\
\hline Kuwait & 3.3 & Kuwait & 4.6 & Kuwait & 3.2 \\
\hline United Arab Emirates & 4.1 & Bahrain & 5.8 & United Arab Emirates & 3.5 \\
\hline Bahrain & 5.7 & Azerbaijan & 6.2 & Iran & 6.0 \\
\hline Qatar & 6.3 & United Arab Emirates & 6.6 & Qatar & 6.4 \\
\hline Azerbaijan & 7.1 & Algeria & 7.0 & Bahrain & 7.7 \\
\hline Iran & 7.8 & Qatar & 7.0 & Azerbaijan & 8.0 \\
\hline Algeria & 9.9 & Libya & 9.9 & Algeria & 9.7 \\
\hline Pakistan & 10.4 & Pakistan & 10.3 & Pakistan & 9.9 \\
\hline Tunisia & 11.1 & Tunisia & 10.6 & Turkmenistan & 10.4 \\
\hline Lebanon & 11.4 & Kyrgyz Republic & 11.8 & Oman & 11.4 \\
\hline Libya & 11.4 & Lebanon & 11.9 & Lebanon & 12.2 \\
\hline Kazakhstan & 12.2 & Syria & 11.9 & Tunisia & 12.2 \\
\hline Syria & 12.6 & Turkmenistan & 12.9 & Egypt & 12.4 \\
\hline Oman & 13.0 & Iran & 13.3 & Syria & 12.7 \\
\hline Egypt & 13.5 & Oman & 13.5 & Libya & 12.9 \\
\hline Morocco & 14.6 & Kazakhstan & 14.4 & Kazakhstan & 13.2 \\
\hline Turkmenistan & 14.9 & Morocco & 15.3 & Morocco & 14.7 \\
\hline Georgia & 17.1 & Georgia & 16.4 & Jordan & 18.7 \\
\hline Jordan & 18.7 & Egypt & 16.9 & Georgia & 18.8 \\
\hline Sudan & 19.2 & Armenia & 19.0 & Sudan & 18.8 \\
\hline Armenia & 20.0 & Sudan & 19.1 & Armenia & 20.6 \\
\hline Kyrgyz Republic & 20.5 & Jordan & 19.9 & Yemen & 21.7 \\
\hline Yemen & 21.8 & Yemen & 21.3 & Kyrgyz Republic & 22.4 \\
\hline Tajikistan & 24.4 & Tajikistan & 24.2 & Uzbekistan & 23.9 \\
\hline Uzbekistan & 24.5 & Mauritania & 25.0 & Tajikistan & 24.8 \\
\hline Mauritania & 26.0 & Uzbekistan & 25.7 & Mauritania & 26.0 \\
\hline
\end{tabular}

Source: Authors' calculations

Scenario 1: Equal weights for distance, GDP, similarity of growth rates, similarity of trade structures, and similarity of inflation performances.

Scenario 2: Weights of 0.1 for distance and GDP, and 0.267 for the remaining variables.

Scenario 3: Weights of 0.25 for distance and GDP, and 0.167 for the remaining variables. 
Table 2a. Country Ranking by SEED Country (Scenario 1)

\begin{tabular}{|c|c|c|c|c|c|c|c|c|}
\hline Algeria & Armenia & Azerbaijan & Bahrain & Egypt & Georgia & Iran & Jordan & Kazakhstan \\
\hline Saudi Arabia & Lebanon & Saudi Arabia & Saudi Arabia & Lebanon & Pakistan & Turkmenistan & Lebanon & Turkmenistan \\
\hline Kuwait & Egypt & Kuwait & Kuwait & Kuwait & Kyrgyz Republic & Azerbaijan & Kuwait & Iran \\
\hline Qatar & Kuwait & United Arab Emirates & United Arab Emirates & Saudi Arabia & Kuwait & United Arab Emirates & Saudi Arabia & United Arab Emirates \\
\hline United Arab Emirates & Saudi Arabia & Bahrain & Qatar & United Arab Emirates & Saudi Arabia & Saudi Arabia & Bahrain & Saudi Arabia \\
\hline Bahrain & United Arab Emirates & Qatar & Oman & Bahrain & United Arab Emirates & Kuwait & United Arab Emirates & Bahrain \\
\hline Azerbaijan & Bahrain & Oman & Azerbaijan & Qatar & Qatar & Bahrain & Qatar & Kuwait \\
\hline Iran & Qatar & Pakistan & Iran & Iran & Bahrain & Syria & Azerbaijan & Syria \\
\hline Pakistan & Iran & Algeria & Pakistan & Azerbaijan & Iran & Sudan & Iran & Azerbaijan \\
\hline Libya & Azerbaijan & Libya & Libya & Pakistan & Azerbaijan & Egypt & Oman & Pakistan \\
\hline Lebanon & Pakistan & Tunisia & Algeria & Algeria & Algeria & Kazakhstan & Pakistan & Algeria \\
\hline Syria & Algeria & Kazakhstan & Tunisia & Tunisia & Tunisia & Algeria & Libya & Libya \\
\hline Egypt & Tunisia & Morocco & Kazakhstan & Kazakhstan & Libya & Libya & Algeria & Egypt \\
\hline Tunisia & Kazakhstan & Lebanon & Morocco & Libya & Kazakhstan & Tunisia & Morocco & Tunisia \\
\hline Kazakhstan & Libya & Syria & Lebanon & Morocco & Egypt & Yemen & Tunisia & Lebanon \\
\hline Morocco & Morocco & Egypt & Syria & Syria & Lebanon & Pakistan & Kazakhstan & Georgia \\
\hline Oman & Syria & Iran & Egypt & Oman & Syria & Qatar & Syria & Qatar \\
\hline Jordan & Oman & Jordan & Jordan & Jordan & Oman & Oman & Egypt & Oman \\
\hline Georgia & Georgia & Georgia & Georgia & Georgia & Turkmenistan & Georgia & Georgia & Armenia \\
\hline Turkmenistan & Turkmenistan & Turkmenistan & Turkmenistan & Turkmenistan & Armenia & Lebanon & Turkmenistan & Jordan \\
\hline Armenia & Kyrgyz Republic & Armenia & Armenia & Armenia & Jordan & Armenia & Armenia & Sudan \\
\hline Kyrgyz Republic & Jordan & Kyrgyz Republic & Kyrgyz Republic & Kyrgyz Republic & Morocco & Kyrgyz Republic & Kyrgyz Republic & Yemen \\
\hline Sudan & Sudan & Sudan & Sudan & Sudan & Sudan & Uzbekistan & Sudan & Kyrgyz Republic \\
\hline Yemen & Yemen & Yemen & Yemen & Yemen & Yemen & Morocco & Yemen & Morocco \\
\hline Tajkistan & Tajikistan & Tajikistan & Tajikistan & Tajikistan & Tajikistan & Jordan & Tajikistan & Uzbekistan \\
\hline Uzbekistan & Uzbekistan & Uzbekistan & Uzbekistan & Uzbekistan & Uzbekistan & Tajkistan & Uzbekistan & Tajikistan \\
\hline Mauritania & Mauritania & Mauritania & Mauritania & Mauritania & Mauritania & Mauritania & Mauritania & Mauritania \\
\hline Kuwait & Kyrgyz Republic & Lebanon & Libya & Mauritania & Morocco & Oman & Pakistan & Qatar \\
\hline Saudi Arabia & Pakistan & Kuwait & Saudi Arabia & Tunisia & Lebanon & Saudi Arabia & Saudi Arabia & Saudi Arabia \\
\hline United Arab Emirates & Tunisia & Saudi Arabia & Kuwait & Egypt & Kuwait & United Arab Emirates & Qatar & United Arab Emirates \\
\hline Qatar & Lebanon & Bahrain & United Arab Emirates & Morocco & Saudi Arabia & Kuwait & Kuwait & Kuwait \\
\hline Bahrain & Kuwait & United Arab Emirates & Qatar & Syria & Bahrain & Bahrain & United Arab Emirates & Bahrain \\
\hline Oman & Saudi Arabia & Oman & Bahrain & Lebanon & Oman & Qatar & Bahrain & Azerbaijan \\
\hline Azerbaijan & Qatar & Azerbaijan & Oman & Georgia & Azerbaijan & Azerbaijan & Azerbaijan & Iran \\
\hline Iran & United Arab Emirates & Qatar & Azerbaijan & Kuwait & Qatar & Iran & Iran & Pakistan \\
\hline Libya & Bahrain & Iran & Iran & Pakistan & Algeria & Libya & Algeria & Oman \\
\hline Algeria & Iran & Libya & Pakistan & Iran & Libya & Algeria & Tunisia & Libya \\
\hline Morocco & Azerbaijan & Algeria & Algeria & Algeria & Tunisia & Morocco & Libya & Algeria \\
\hline Tunisia & Algeria & Morocco & Tunisia & Kazakhstan & United Arab Emirates & Tunisia & Kazakhstan & Tunisia \\
\hline Kazakhstan & Libya & Tunisia & Kazakhstan & Saudi Arabia & Iran & Kazakhstan & Morocco & Kazakhstan \\
\hline Lebanon & Kazakhstan & Kazakhstan & Morocco & United Arab Emirates & Pakistan & Lebanon & Lebanon & Morocco \\
\hline Syria & Morocco & Syria & Lebanon & Oman & Turkmenistan & Syria & Syria & Lebanon \\
\hline Egypt & Syria & Egypt & Syria & Qatar & Syria & Egypt & Oman & Syria \\
\hline Jordan & Oman & Jordan & Egypt & Bahrain & Jordan & Jordan & Egypt & Egypt \\
\hline Georgia & Egypt & Georgia & Jordan & Azerbaijan & Egypt & Georgia & Jordan & Jordan \\
\hline Turkmenistan & Jordan & Turkmenistan & Georgia & Turkmenistan & Georgia & Turkmenistan & Georgia & Georgia \\
\hline Pakistan & Georgia & Pakistan & Turkmenistan & Armenia & Kazakhstan & Pakistan & Turkmenistan & Turkmenistan \\
\hline Kyrgyz Republic & Turkmenistan & Kyrgyz Republic & Armenia & Jordan & Sudan & Kyrgyz Republic & Armenia & Armenia \\
\hline Armenia & Armenia & Armenia & Kyrgyz Republic & Libya & Yemen & Armenia & Kyrgyz Republic & Kyrgyz Republic \\
\hline Sudan & Sudan & Sudan & Sudan & Sudan & Armenia & Sudan & Sudan & Sudan \\
\hline Yemen & Yemen & Yemen & Yemen & Yemen & Kyrgyz Republic & Yemen & Yemen & Yemen \\
\hline Tajkistan & Tajikistan & Tajikistan & Tajikistan & Kyrgyz Republic & Uzbekistan & Tajikistan & Tajikistan & Tajikistan \\
\hline Uzbekistan & Uzbekistan & Uzbekistan & Uzbekistan & Uzbekistan & $\begin{array}{l}\text { Tajikistan } \\
\text { The }\end{array}$ & Uzbekistan & Uzbekistan & Uzbekistan \\
\hline Mauritania & Mauritania & Mauritania & Mauritania & Tajikistan & Mauritania & Mauritania & Mauritania & Mauritania \\
\hline
\end{tabular}


Table 2a (concluded). Country Ranking by SEED Country (Scenario 1)

\begin{tabular}{|c|c|c|c|c|c|c|c|c|}
\hline Saudi Arabia & Sudan & Syria & Tajikistan & Tunisia & Turkmenistan & United Arab Emirates & Uzbekistan & Yemen \\
\hline Kuwait & United Arab Emirates & Kuwait & Iran & Morocco & United Arab Emirates & Saudi Arabia & United Arab Emirates & Saudi Arabia \\
\hline United Arab Emirates & Saudi Arabia & Saudi Arabia & Turkmenistan & Lebanon & Saudi Arabia & Oatar & Turkmenistan & United Arab Emirates \\
\hline Qatar & Qatar & United Arab Emirates & Azerbaijan & Algeria & Qatar & Kuwait & Sudan & Sudan \\
\hline Bahrain & Kuwait & Qatar & United Arab Emirates & Kuwait & Kuwait & Bahrain & Saudi Arabia & Qatar \\
\hline Oman & Bahrain & Bahrain & Saudi Arabia & Saudi Arabia & Azerbaijan & Azerbaijan & Qatar & Kuwait \\
\hline Azerbaijan & Iran & Azerbaijan & Kuwait & Qatar & Iran & Pakistan & Bahrain & Bahrain \\
\hline Iran & Turkmenistan & Iran & Bahrain & Bahrain & Syria & Algeria & Kuwait & Iran \\
\hline Libya & Azerbaijan & Pakistan & Kazakhstan & Oman & Pakistan & Tunisia & Iran & Turkmenistan \\
\hline Algeria & Pakistan & Algeria & Syria & Azerbaijan & Bahrain & Libya & Azerbaijan & Azerbaijan \\
\hline Morocco & Kazakhstan & Tunisia & Sudan & United Arab Emirates & Algeria & Kazakhstan & Syria & Pakistan \\
\hline Tunisia & Syria & Libya & Egypt & Iran & Libya & Morocco & Pakistan & Kazakhstan \\
\hline Kazakhstan & Egypt & Kazakhstan & Algeria & Pakistan & Kazakhstan & Lebanon & Kazakhstan & Syria \\
\hline Syria & Tunisia & Lebanon & Tunisia & Syria & Tunisia & Iran & Libya & Algeria \\
\hline Egypt & Libya & Georgia & Yemen & Egypt & Lebanon & Oman & Egypt & Tunisia \\
\hline Jordan & Morocco & Armenia & Pakistan & Kazakhstan & Georgia & Turkmenistan & Tunisia & Libya \\
\hline Georgia & Lebanon & Oman & Qatar & Jordan & Armenia & Georgia & Yemen & Morocco \\
\hline Turkmenistan & Georgia & Turkmenistan & Oman & Georgia & Oman & Jordan & Georgia & Georgia \\
\hline Pakistan & Armenia & Kyrgyz Republic & Georgia & Turkmenistan & Jordan & Egypt & Armenia & Lebanon \\
\hline Kyrgyz Republic & Oman & $\begin{array}{l}\text { Morocco } \\
\text { lation }\end{array}$ & Lebanon & Armenia & Sudan & Sudan & Lebanon & Oman \\
\hline Armenia & Jordan & Jordan & Kyrgyz Republic & Kyrgyz Republic & Yemen & Yemen & Kyrgyz Republic & Jordan \\
\hline Sudan & Yemen & Sudan & Uzbekistan & Sudan & Kyrgyz Republic & Armenia & Morocco & Armenia \\
\hline Yemen & Kyrgyz Republic & Yemen & Armenia & Yemen & Morocco & Kyrgyz Republic & Jordan & Kyrgyz Republic \\
\hline Tajikistan & Uzbekistan & Tajikistan & Morocco & Tajkistan & Uzbekistan & Uzbekistan & Oman & Uzbekistan \\
\hline Uzbekistan & Tajikistan & Uzbekistan & Jordan & Uzbekistan & Tajikistan & Tajikistan & Tajikistan & Tajkistan \\
\hline
\end{tabular}


Table 2b. Country Ranking by SEED Country (Scenario 2)

\begin{tabular}{|c|c|c|c|c|c|c|c|c|}
\hline Algeria & Armenia & Azerbaijan & Bahrain & Egypt & Georgia & Iran & Jordan & Kazakhstan \\
\hline Saudi Arabia & Lebanon & Bahrain & Saudi Arabia & Lebanon & Armenia & Turkmenistan & Morocco & Turkmenistan \\
\hline Qatar & Egypt & Saudi Arabia & Kuwait & Tunisia & Lebanon & Azerbaijan & Lebanon & United Arab Emirates \\
\hline Bahrain & Tunisia & Kuwait & Qatar & Morocco & Pakistan & Kazakhstan & Kuwait & Azerbaijan \\
\hline Kuwait & Morocco & Qatar & United Arab Emirates & Algeria & Kuwait & United Arab Emirates & Saudi Arabia & Saudi Arabia \\
\hline Azerbaijan & Algeria & Algeria & Azerbaijan & Kuwait & Kyrgyz Republic & Sudan & Azerbaijan & Bahrain \\
\hline United Arab Emirates & Kuwait & United Arab Emirates & Libya & Syria & Tunisia & Saudi Arabia & Algeria & Kuwait \\
\hline Libya & Syria & Libya & Algeria & Saudi Arabia & Egypt & Bahrain & Bahrain & Qatar \\
\hline Tunisia & Saudi Arabia & Tunisia & Tunisia & Qatar & Algeria & Yemen & Qatar & Syria \\
\hline Oman & Qatar & Pakistan & Oman & Azerbaijan & Morocco & Syria & Oman & Kyrgyz Republic \\
\hline Pakistan & Azerbaijan & Kyrgyz Republic & Pakistan & Bahrain & Syria & Kuwait & Pakistan & Pakistan \\
\hline Kyrgyz Republic & Bahrain & Iran & Kyrgyz Republic & United Arab Emirates & Azerbaijan & Algeria & United Arab Emirates & Libya \\
\hline Iran & United Arab Emirates & Turkmenistan & Lebanon & Oman & Saudi Arabia & Libya & Libya & Algeria \\
\hline Turkmenistan & Oman & Oman & Iran & Pakistan & Qatar & Egypt & Tunisia & Tunisia \\
\hline Lebanon & Pakistan & Kazakhstan & Syria & Kyrgyz Republic & United Arab Emirates & Pakistan & Kyrgyz Republic & Georgia \\
\hline Syria & Kyrgyz Republic & Lebanon & Morocco & Libya & Bahrain & Georgia & Georgia & Iran \\
\hline Morocco & Libya & Syria & Kazakhstan & Georgia & Oman & Kyrgyz Republic & Iran & Armenia \\
\hline Kazakhstan & Georgia & Jordan & Jordan & Iran & Iran & Qatar & Syria & Oman \\
\hline Jordan & Iran & Egypt & Georgia & Kazakhstan & Kazakhstan & Oman & Turkmenistan & Sudan \\
\hline Egypt & Kazakhstan & Georgia & Turkmenistan & Turkmenistan & Libya & Tunisia & Kazakhstan & Egypt \\
\hline Georgia & Turkmenistan & Armenia & Egypt & Jordan & Turkmenistan & Lebanon & Egypt & Lebanon \\
\hline Armenia & Jordan & Morocco & Armenia & Armenia & Jordan & Uzbekistan & Armenia & Morocco \\
\hline Sudan & Sudan & Sudan & Sudan & Sudan & Sudan & Armenia & Sudan & Jordan \\
\hline Yemen & Yemen & Yemen & Yemen & Yemen & Yemen & Morocco & Yemen & Yemen \\
\hline Tajikistan & Tajikistan & Tajikistan & Tajikistan & Tajikistan & Tajikistan & Jordan & Tajikistan & Tajikistan \\
\hline Mauritania & Mauritania & Mauritania & Mauritania & Mauritania & Mauritania & Tajikistan & Mauritania & Mauritania \\
\hline Uzbekistan & Uzbekistan & Uzbekistan & Uzbekistan & Uzbekistan & Uzbekistan & Mauritania & Uzbekistan & Uzbekistan \\
\hline Kuwait & Kyrgyz Republic & Lebanon & Libya & Mauritania & Morocco & Oman & Pakistan & Qatar \\
\hline Saudi Arabia & Pakistan & Morocco & Saudi Arabia & Georgia & Lebanon & Saudi Arabia & Tunisia & Saudi Arabia \\
\hline Bahrain & Tunisia & Kuwait & Kuwait & Armenia & Kuwait & Kuwait & Kuwait & Bahrain \\
\hline Qatar & Kuwait & Saudi Arabia & Bahrain & Lebanon & Saudi Arabia & Bahrain & Saudi Arabia & United Arab Emirates \\
\hline United Arab Emirates & Saudi Arabia & Bahrain & Algeria & Syria & Bahrain & United Arab Emirates & Qatar & Kuwait \\
\hline Libya & Qatar & Algeria & Azerbaijan & Egypt & Algeria & Libya & Algeria & Azerbaijan \\
\hline Azerbaijan & Algeria & Azerbaijan & Qatar & Kuwait & Azerbaijan & Azerbaijan & Bahrain & Libya \\
\hline Algeria & Bahrain & Qatar & United Arab Emirates & Bahrain & Qatar & Qatar & Azerbaijan & Algeria \\
\hline Tunisia & United Arab Emirates & Oman & Oman & Algeria & Oman & Algeria & United Arab Emirates & Tunisia \\
\hline Oman & Azerbaijan & Pakistan & Pakistan & Saudi Arabia & Pakistan & Tunisia & Libya & Pakistan \\
\hline Pakistan & Libya & United Arab Emirates & Kyrgyz Republic & United Arab Emirates & United Arab Emirates & Pakistan & Lebanon & Kyrgyz Republic \\
\hline Kyrgyz Republic & Lebanon & Libya & Iran & Azerbaijan & Libya & Kyrgyz Republic & Iran & Iran \\
\hline Iran & Iran & Tunisia & Turkmenistan & Qatar & Tunisia & Iran & Syria & Turkmenistan \\
\hline Turkmenistan & Syria & Kyrgyz Republic & Kazakhstan & Oman & Kyrgyz Republic & Turkmenistan & Oman & Oman \\
\hline Lebanon & Oman & Iran & Syria & Kyrgyz Republic & Iran & Lebanon & Kyrgyz Republic & Kazakhstan \\
\hline Syria & Morocco & Syria & Lebanon & Pakistan & Syria & Syria & Morocco & Lebanon \\
\hline Morocco & Kazakhstan & Georgia & Morocco & Tunisia & Georgia & Morocco & Kazakhstan & Syria \\
\hline Kazakhstan & Jordan & Turkmenistan & Jordan & Libya & Turkmenistan & Kazakhstan & Jordan & Jordan \\
\hline Jordan & Georgia & Kazakhstan & Tunisia & Kazakhstan & Kazakhstan & Jordan & Georgia & Egypt \\
\hline Egypt & Turkmenistan & Jordan & Egypt & Morocco & Jordan & Egypt & Turkmenistan & Georgia \\
\hline Georgia & Egypt & Egypt & Georgia & Iran & Egypt & Georgia & Egypt & Armenia \\
\hline Armenia & Armenia & Armenia & Armenia & Turkmenistan & Armenia & Armenia & Armenia & Morocco \\
\hline Sudan & Sudan & Sudan & Sudan & Sudan & Sudan & Sudan & Sudan & Sudan \\
\hline Yemen & Yemen & Yemen & Yemen & Jordan & Yemen & Yemen & Yemen & Yemen \\
\hline Tajikistan & Tajikistan & Tajikistan & Tajikistan & Yemen & Tajikistan & Tajikistan & Tajikistan & Tajikistan \\
\hline Mauritania & Mauritania & Mauritania & Mauritania & Uzbekistan & Mauritania & Mauritania & Mauritania & Muuritania \\
\hline Uzbekistan & Uzbekistan & Uzbekistan & Uzbekistan & Tajikistan & Uzbekistan & Uzbekistan & Uzbekistan & Uzbekistan \\
\hline
\end{tabular}


Table 2b (concluded). Country Ranking by SEED Country (Scenario 2)

\begin{tabular}{|c|c|c|c|c|c|c|c|c|}
\hline Saudi Arabia & Sudan & Syria & Tajikistan & Tunisia & Turkmenistan & United Arab Emirates & Uzbekistan & Yemen \\
\hline Kuwait & Turkmenistan & Kuwait & Iran & Morocco & United Arab Emirates & Saudi Arabia & Sudan & Syria \\
\hline Bahrain & Kazakhstan & Algeria & Turkmenistan & Lebanon & Saudi Arabia & Qatar & Turkmenistan & Algeria \\
\hline Qatar & Libya & Saudi Arabia & Azerbaijan & Kuwait & Qatar & Bahrain & United Arab Emirates & Qatar \\
\hline United Arab Emirates & United Arab Emirates & Qatar & Kazakhstan & Algeria & Bahrain & Kuwait & Kazakhstan & Saudi Arabia \\
\hline Libya & Azerbaijan & United Arab Emirates & United Arab Emirates & Saudi Arabia & Azerbaijan & Azerbaijan & Azerbaijan & United Arab Emirates \\
\hline Azerbaijan & Bahrain & Azerbaijan & Sudan & Azerbaijan & Kuwait & Algeria & Libya & Sudan \\
\hline Algeria & Saudi Arabia & Bahrain & Saudi Arabia & Bahrain & Algeria & Libya & Yemen & Bahrain \\
\hline Tunisia & Kuwait & Pakistan & Bahrain & Qatar & Libya & Tunisia & Saudi Arabia & Azerbaijan \\
\hline Oman & Oatar & Kyrayz Republic & Yemen & Oman & Syria & Pakistan & Bahrain & Kuwait \\
\hline Pakistan & Syria & Libya & Syria & Pakistan & Kyrgyz Republic & Kyrgyz Republic & Kuwait & Turkmenistan \\
\hline Kyrgyz Republic & Kyrgyz Republic & Tunisia & Kuwait & United Arab Emirates & Pakistan & Iran & Qatar & Kazakhstan \\
\hline Iran & Pakistan & Georgia & Algeria & Libya & Iran & Turkmenistan & Syria & Kyrgyz Republic \\
\hline Lebanon & Tunisia & Lebanon & Egypt & Iran & Kazakhstan & Kazakhstan & Iran & Libya \\
\hline Syria & Georgia & Turkmenistan & Pakistan & Turkmenistan & Tunisia & Lebanon & Pakistan & Tunisia \\
\hline Morocco & Iran & Armenia & Georgia & Syria & Egypt & Syria & Algeria & Georgia \\
\hline Kazakhstan & Lebanon & Oman & Kyrgyz Republic & Georgia & Lebanon & Jordan & Georgia & Iran \\
\hline Jordan & Oman & Kazakhstan & Qatar & Jordan & Armenia & Egypt & Egypt & Egypt \\
\hline Egypt & Egypt & Egypt & Oman & Egypt & Oman & Georgia & Tunisia & Lebanon \\
\hline Georgia & Jordan & Morocco & Tunisia & Kazakhstan & Morocco & Armenia & Lebanon & Armenia \\
\hline Armenia & Armenia & Sudan & Lebanon & Armenia & Sudan & Morocco & Armenia & Morocco \\
\hline Sudan & Morocco & Jordan & Morocco & Sudan & Jordan & Sudan & Morocco & Oman \\
\hline Yemen & Yemen & Yemen & Uzbekistan & Yemen & Yemen & Yemen & Mauritania & Jordan \\
\hline Tajikistan & Tajikistan & Tajikistan & Armenia & Tajikistan & Tajikistan & Tajikistan & Oman & Tajikistan \\
\hline Mauritania & Mauritania & Mauritania & Mauritania & Mauritania & Mauritania & Mauritania & Jordan & Mauritania \\
\hline Uzbekistan & Uzbekistan & Uzbekistan & Jordan & Uzbekistan & Uzbekistan & Uzbekistan & Tajikistan & Uzbekistan \\
\hline
\end{tabular}


Table 2c. Country Ranking by SEED Country (Scenario 3)

\begin{tabular}{|c|c|c|c|c|c|c|c|c|}
\hline Algeria & Armenia & Azerbaijan & Bahrain & Egypt & Georgia & Iran & Jordan & Kazakhstan \\
\hline Saudi Arabia & Lebanon & Iran & Saudi Arabia & Lebanon & Pakistan & Turkmenistan & Lebanon & Algeria \\
\hline Kuwait & Egypt & Kuwait & Kuwait & Kuwait & Kuwait & United Arab Emirates & Kuwait & Libya \\
\hline Qatar & Kuwait & Saudi Arabia & United Arab Emirates & Saudi Arabia & Saudi Arabia & Saudi Arabia & Saudi Arabia & Egypt \\
\hline United Arab Emirates & Saudi Arabia & United Arab Emirates & Qatar & United Arab Emirates & United Arab Emirates & Kuwait & United Arab Emirates & Syria \\
\hline Bahrain & United Arab Emirates & Bahrain & Oman & Bahrain & Qatar & Bahrain & Qatar & Kuwait \\
\hline Iran & Iran & Oman & Iran & Iran & Iran & Azerbaijan & Bahrain & Saudi Arabia \\
\hline Azerbaijan & Azerbaijan & Qatar & Azerbaijan & Azerbaijan & Bahrain & Syria & Oman & United Arab Emirates \\
\hline Pakistan & Pakistan & Pakistan & Pakistan & Pakistan & Azerbaijan & Egypt & Iran & \\
\hline Turkmenistan & Oman & Turkmenistan & Turkmenistan & Oman & Turkmenistan & Sudan & Azerbaijan & Turkmenistan \\
\hline Oman & Qatar & Algeria & Libya & Qatar & Algeria & Kazakhstan & Pakistan & Azerbaijan \\
\hline Libya & Bahrain & Tunisia & Algeria & Algeria & Tunisia & Algeria & Turkmenistan & Bahrain \\
\hline Lebanon & Algeria & Libya & Tunisia & Tunisia & Kazakhstan & Tunisia & Libya & Qatar \\
\hline Syria & Tunisia & Kazakhstan & Kazakhstan & Kazakhstan & Libya & Libya & Algeria & Oman \\
\hline Egypt & Kazakhstan & Morocco & Morocco & Libya & Egypt & Morocco & Tunisia & Pakistan \\
\hline Tunisia & Libya & Lebanon & Lebanon & Morocco & Lebanon & Lebanon & Kazakhstan & Kyrgyz Republic \\
\hline Kazakhstan & Syria & Syria & Syria & Syria & Syria & Georgia & Morocco & Georgia \\
\hline Morocco & Morocco & Jordan & Jordan & Jordan & Sudan & Armenia & Egypt & Lebanon \\
\hline Jordan & Jordan & Egypt & Egypt & Georgia & Oman & Qatar & Syria & Armenia \\
\hline Georgia & Georgia & Georgia & Georgia & Turkmenistan & Jordan & Oman & Georgia & Tunisia \\
\hline Sudan & Turkmenistan & Sudan & Sudan & Armenia & Armenia & Yemen & Sudan & Morocco \\
\hline Armenia & Kyrgyz Republic & Armenia & Armenia & Kyrgyz Republic & Yemen & Pakistan & Armenia & Jordan \\
\hline Yemen & Sudan & Yemen & Yemen & Sudan & Kyrgyz Republic & Uzbekistan & Yemen & Sudan \\
\hline Kyrgyz Republic & Yemen & Kyrgyz Republic & Kyrgyz Republic & Yemen & Morocco & Kyrgyz Republic & Kyrgyz Republic & Yemen \\
\hline Uzbekistan & Tajikistan & Uzbekistan & Uzbekistan & Tajikistan & Uzbekistan & Jordan & Uzbekistan & Tajikistan \\
\hline Tajikistan & Uzbekistan & Tajkistan & Tajikistan & Uzbekistan & Tajikistan & Tajikistan & Tajikistan & Uzbekistan \\
\hline Mauritania & Mauritania & Mauritania & Mauritania & Mauritania & Mauritania & Mauritania & Mauritania & Mauritania \\
\hline Kuwait & Kyrgyz Republic & Lebanon & Libya & Mauritania & Morocco & Oman & Pakistan & Qatar \\
\hline Saudi Arabia & Pakistan & Kuwait & Algeria & $\begin{array}{l}\text { Tunisia } \\
\text { Tha }\end{array}$ & Lebanon & Saudi Arabia & Saudi Arabia & Saudi Arabia \\
\hline United Arab Emirates & Saudi Arabia & Saudi Arabia & Saudi Arabia & Egypt & Algeria & United Arab Emirates & United Arab Emirates & United Arab Emirates \\
\hline Qatar & United Arab Emirates & United Arab Emirates & Kuwait & Morocco & Kuwait & Kuwait & Qatar & Kuwait \\
\hline Oman & Qatar & Oman & United Arab Emirates & Syria & Saudi Arabia & Qatar & Kuwait & Bahrain \\
\hline Bahrain & Kuwait & Qatar & Qatar & Lebanon & Bahrain & Bahrain & Iran & Iran \\
\hline Iran & Iran & Bahrain & Bahrain & Kuwait & Oman & Iran & Bahrain & Azerbaijan \\
\hline Azerbaijan & Bahrain & Iran & Oman & Saudi Arabia & United Arab Emirates & Azerbaijan & Azerbaijan & Pakistan \\
\hline Pakistan & Azerbaijan & Azerbaijan & Iran & United Arab Emirates & $\begin{array}{l}\text { Iran } \\
\end{array}$ & $\begin{array}{l}\text { Pakistan } \\
\text { Pan }\end{array}$ & Algeria & Turkmenistan \\
\hline Turkmenistan & Algeria & Pakistan & Azerbaijan & Qatar & Azerbaijan & Turkmenistan & Tunisia & Oman \\
\hline Libya & Tunisia & Turkmenistan & Pakistan & $\begin{array}{l}\text { Iran } \\
\text { I }\end{array}$ & Qtar & Libya & Libya & Algeria \\
\hline Algeria & Libya & Libya & Turkmenistan & Azerbaijan & Pakistan & Algeria & Kazakhstan & Tunisia \\
\hline Tunisia & Kazakhstan & Algeria & Lebanon & Pakistan & Turkmenistan & Tunisia & Morocco & Libya \\
\hline Kazakhstan & Morocco & Morocco & Syria & Oman & Libya & Kazakhstan & Lebanon & Kazakhstan \\
\hline Morocco & Lebanon & Tunisia & Egypt & Bahrain & Syria & Morocco & Syria & Morocco \\
\hline Lebanon & Syria & Kazakhstan & Tunisia & Turkmenistan & Egypt & Lebanon & Egypt & Lebanon \\
\hline Syria & Egypt & Syria & Kazakhstan & Algeria & Tunisia & Syria & Oman & Syria \\
\hline Jordan & Oman & Jordan & Morocco & Kazakhstan & Kazakhstan & Jordan & Jordan & Jordan \\
\hline Egypt & Jordan & Egypt & Jordan & Libya & Jordan & Egypt & Georgia & Egypt \\
\hline Georgia & Georgia & Georgia & Georgia & Sudan & Georgia & Georgia & Turkmenistan & Georgia \\
\hline Sudan & Turkmenistan & Sudan & Sudan & Jordan & Armenia & Sudan & Armenia & Sudan \\
\hline Armenia & Armenia & Yemen & Armenia & Georgia & Sudan & Armenia & Kyrgyz Republic & Armenia \\
\hline Yemen & Sudan & Armenia & Yemen & Armenia & Yemen & Yemen & Sudan & Yemen \\
\hline Kyrgyz Republic & Yemen & Kyrgyz Republic & Kyrgyz Republic & Yemen & Kyrgyz Republic & Kyrgyz Republic & Yemen & Kyrgyz Republic \\
\hline Uzbekistan & Tajikistan & Uzbekistan & Uzbekistan & Kyrgyz Republic & Uzbekistan & Uzbekistan & Tajikistan & Uzbekistan \\
\hline Tajikistan & Uzbekistan & $\begin{array}{l}\text { Tajikistan } \\
\text { The }\end{array}$ & $\begin{array}{l}\text { Tajikistan } \\
\text { The }\end{array}$ & $\begin{array}{l}\text { Uzbekistan } \\
\text { Untion }\end{array}$ & $\begin{array}{l}\text { Tajikistan } \\
\text { The }\end{array}$ & $\begin{array}{l}\text { Tajikistan } \\
\text { Then }\end{array}$ & Uzbekistan & $\begin{array}{l}\text { Tajikistan } \\
\text { The }\end{array}$ \\
\hline Mauritania & Mauritania & Mauritania & Mauritania & Tajikistan & Mauritania & Mauritania & Mauritania & Mauritania \\
\hline
\end{tabular}


Table 2c (concluded). Country Ranking by SEED Country (Scenario 3)

\begin{tabular}{|c|c|c|c|c|c|c|c|c|}
\hline Saudi Arabia & Sudan & Syria & Tajikistan & Tunisia & Turkmenistan & United Arab Emirates & Uzbekistan & Yemen \\
\hline Kuwait & United Arab Emirates & Egypt & Iran & Morocco & United Arab Emirates & Saudi Arabia & United Arab Emirates & Saudi Arabia \\
\hline United Arab Emirates & Saudi Arabia & Lebanon & Turkmenistan & Algeria & Saudi Arabia & Qatar & Turkmenistan & United Arab Emirates \\
\hline Qatar & Qatar & Kuwait & United Arab Emirates & Kuwait & Qatar & Kuwait & Saudi Arabia & Qatar \\
\hline Oman & Kuwait & Saudi Arabia & Saudi Arabia & Saudi Arabia & Kuwait & Bahrain & Iran & Kuwait \\
\hline Bahrain & Iran & United Arab Emirates & Kuwait & Qatar & Iran & Iran & Kuwait & Iran \\
\hline Iran & Turkmenistan & Qatar & Syria & United Arab Emirates & Azerbaijan & Azerbaijan & Bahrain & Turkmenistan \\
\hline Azerbaijan & Azerbaijan & Iran & Egypt & Bahrain & Syria & Pakistan & Azerbaijan & Azerbaijan \\
\hline Pakistan & Syria & Azerbaijan & Kazakhstan & Oman & Egypt & Turkmenistan & Syria & Pakistan \\
\hline Turkmenistan & Egypt & Pakistan & Algeria & Iran & Bahrain & Algeria & Egypt & Kazakhstan \\
\hline Libya & Kazakhstan & Algeria & Tunisia & Azerbaijan & Pakistan & Tunisia & Sudan & Syria \\
\hline Algeria & Algeria & Tunisia & Sudan & Pakistan & Oman & Libya & Qatar & Egypt \\
\hline Tunisia & Tunisia & Kazakhstan & Yemen & Turkmenistan & Algeria & Kazakhstan & Pakistan & Sudan \\
\hline Kazakhstan & Libya & Morocco & Bahrain & Lebanon & Tunisia & Morocco & Kazakhstan & Bahrain \\
\hline Morocco & Morocco & Libya & Qatar & Syria & Kazakhstan & Lebanon & Algeria & Oman \\
\hline Lebanon & Lebanon & Bahrain & Oman & Jordan & Libya & Syria & Tunisia & Algeria \\
\hline Syria & Bahrain & Oman & Azerbaijan & Egypt & Morocco & Egypt & Libya & Tunisia \\
\hline Jordan & Georgia & Turkmenistan & Pakistan & Libya & Lebanon & Oman & Morocco & Libya \\
\hline Egypt & Oman & Georgia & Uzbekistan & Kazakhstan & Sudan & Jordan & Lebanon & Morocco \\
\hline Georgia & Armenia & Armenia & Kyrgyz Republic & Georgia & Jordan & Georgia & Georgia & Lebanon \\
\hline Sudan & Jordan & Jordan & Georgia & Sudan & Georgia & Armenia & Yemen & Georgia \\
\hline Armenia & Yemen & Sudan & Lebanon & Armenia & Armenia & Sudan & Oman & Armenia \\
\hline Yemen & Pakistan & Yemen & Armenia & Yemen & Uzbekistan & Yemen & Jordan & Jordan \\
\hline Kyrgyz Republic & Kyrgyz Republic & Kyrgyz Republic & Jordan & Kyrgyz Republic & Kyrgyz Republic & Kyrgyz Republic & Armenia & Kyrgyz Republic \\
\hline Uzbekistan & Uzbekistan & Uzbekistan & Libya & Uzbekistan & Tajikistan & Uzbekistan & Kyrgyz Republic & Uzbekistan \\
\hline Tajikistan & Tajikistan & Tajikistan & Morocco & Tajikistan & Yemen & Tajikistan & Tajikistan & Tajikistan \\
\hline Mauritania & Mauritania & Muuritania & Mauritania & Mauritania & Mauritania & Muuritania & Mauritania & Mauritania \\
\hline
\end{tabular}




\section{Figure 1. Pakistan (SEED): Currency Maps}

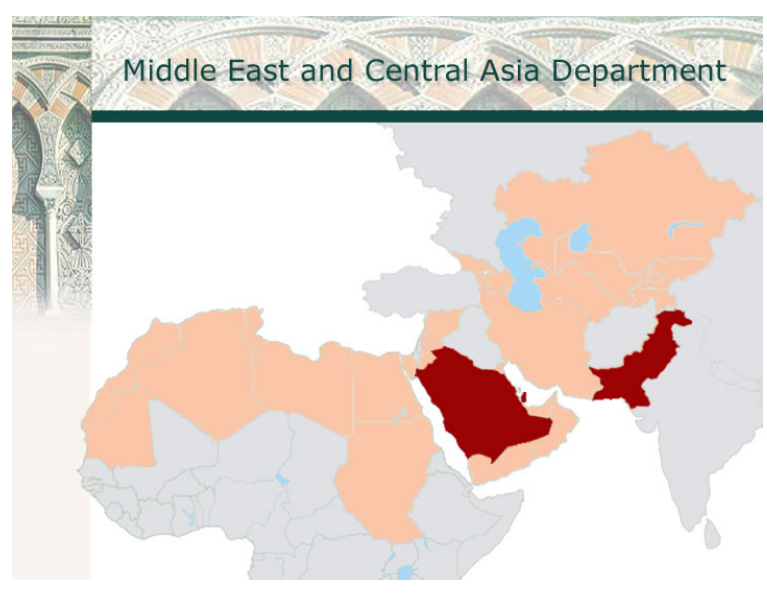

CU comprising three countries (Pakistan, Saudi Arabia, and Qatar)

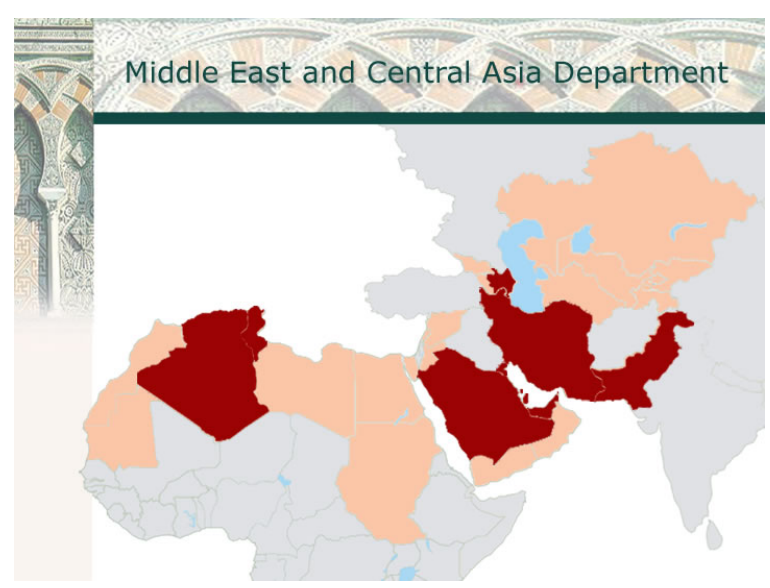

CU comprising ten countries (Pakistan, Saudi Arabia, Qatar, Kuwait, the U.A.E., Bahrain, Azerbaijan, Iran, Algeria, and Tunisia)

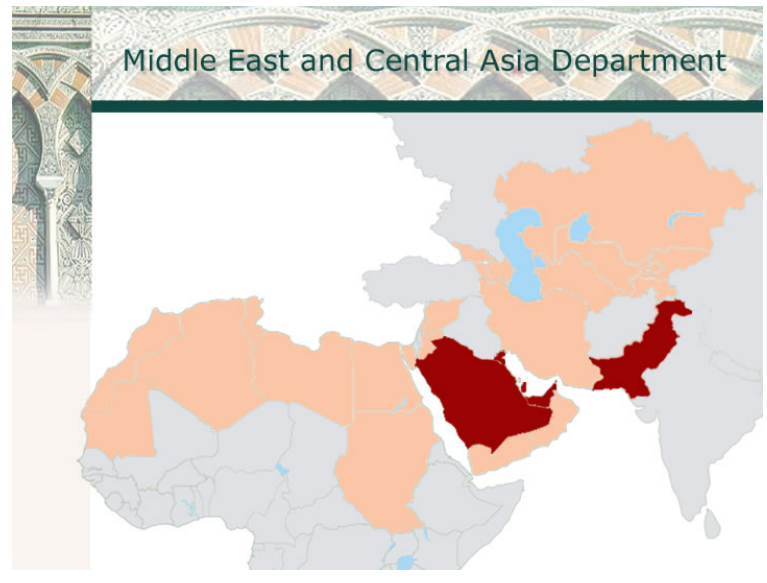

CU comprising five countries (Pakistan, Saudi Arabia, Qatar, Kuwait, and the U.A.E.)

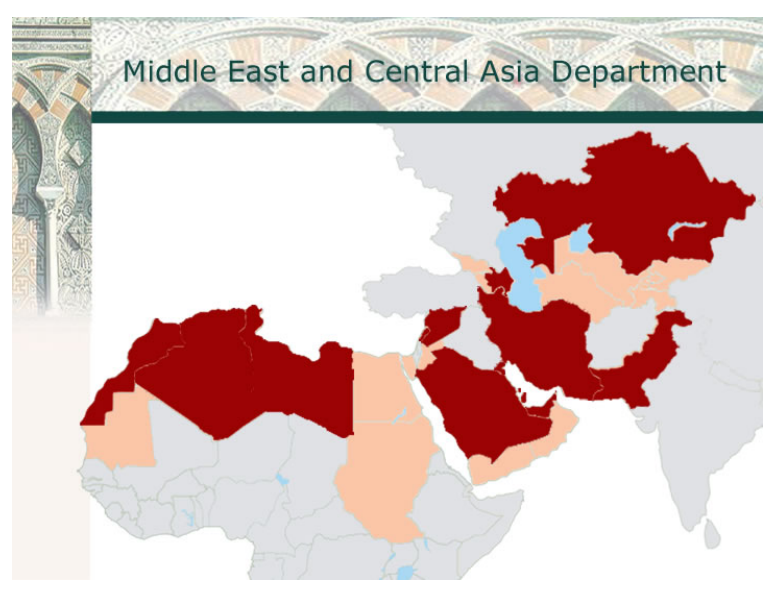

CU comprising 15 countries (Pakistan, Saudi Arabia, Qatar, Kuwait, the U.A.E., Bahrain, Azerbaijan, Iran, Algeria, Tunisia, Libya, Kazakhstan, Morocco, Lebanon, and Syria) 
Figure 2. Algeria (SEED): Currency Maps

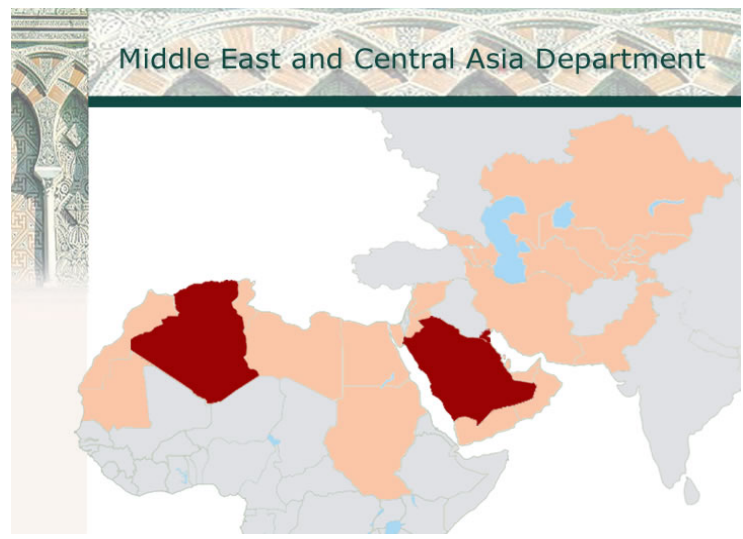

CU comprising three countries (Algeria, Saudi Arabia, and Kuwait)

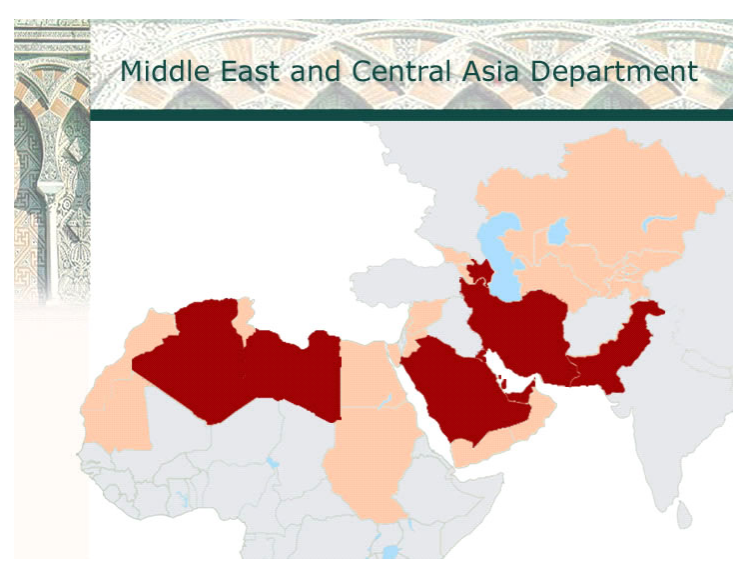

CU comprising ten countries (Algeria, Saudi Arabia, Kuwait, Qatar, the U.A.E., Bahrain, Azerbaijan, Iran, Pakistan, and Libya)

Source: Authors' calculations.

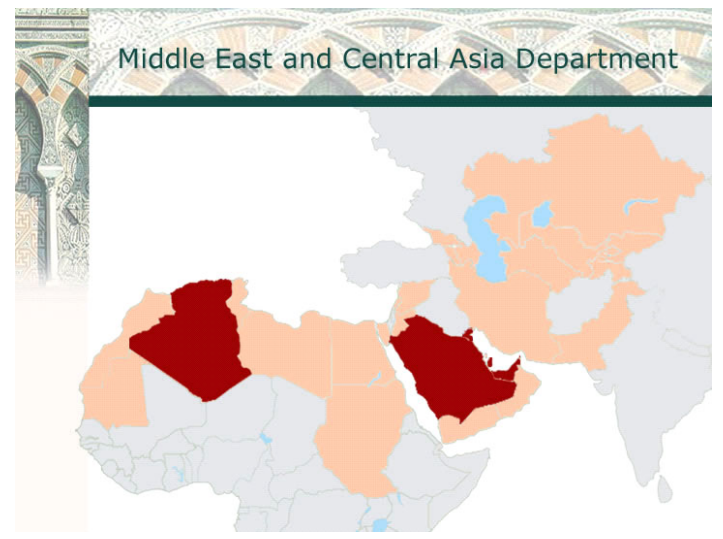

CU comprising five countries (Algeria, Saudi Arabia, Kuwait, Qatar, and the U.A.E.)

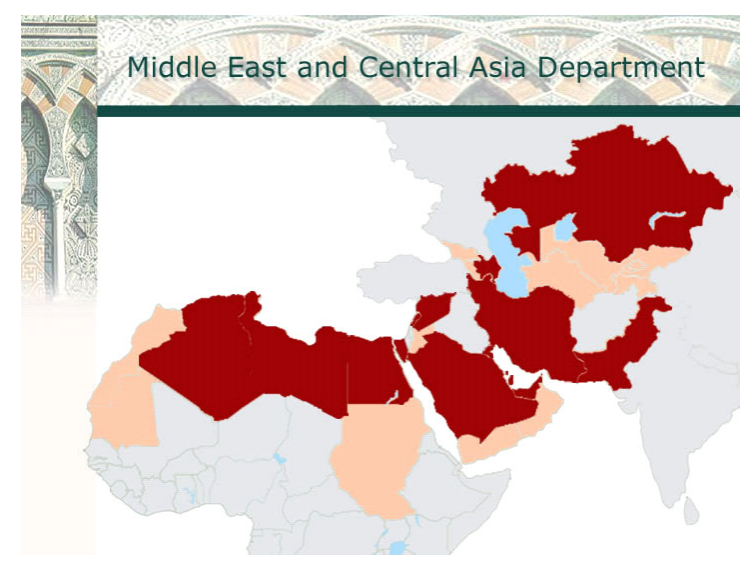

CU comprising 15 countries (Algeria, Saudi Arabia, Kuwait, Qatar, the U.A.E., Bahrain, Azerbaijan, Iran, Pakistan, Libya, Lebanon, Syria, Egypt, Tunisia, and Kazakhstan) 
Figure 3. Azerbaijan (SEED): Currency Maps

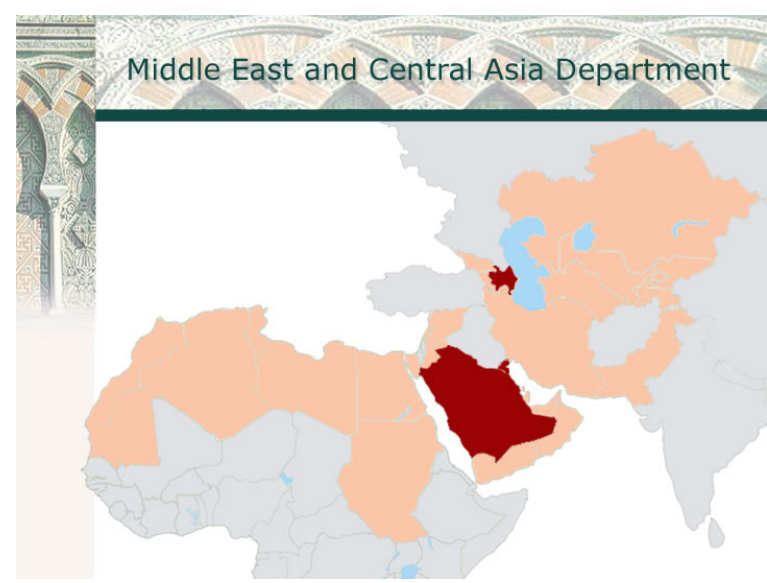

CU comprising three countries (Azerbaijan, Saudi Arabia, and Kuwait)

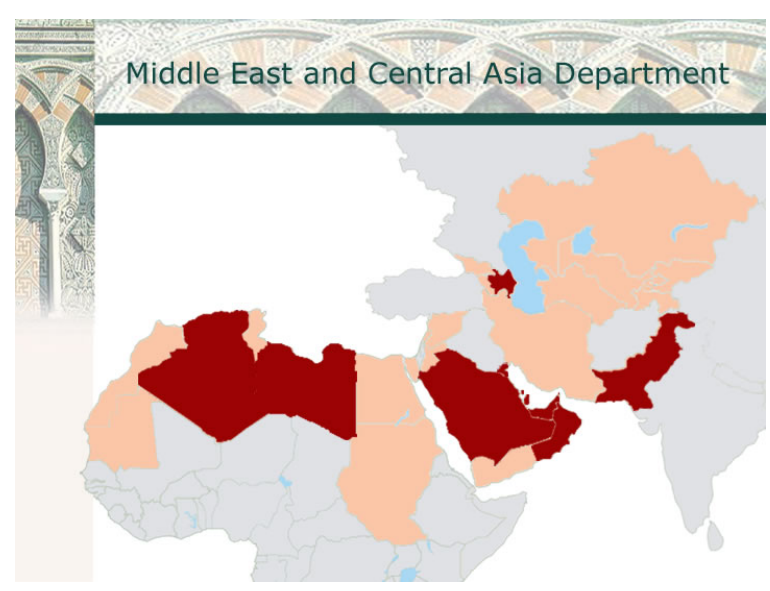

CU comprising ten countries (Azerbaijan, Saudi Arabia, Kuwait, the U.A.E., Bahrain, Qatar, Oman, Pakistan, Algeria, and Libya)

Source: Authors’ calculations.

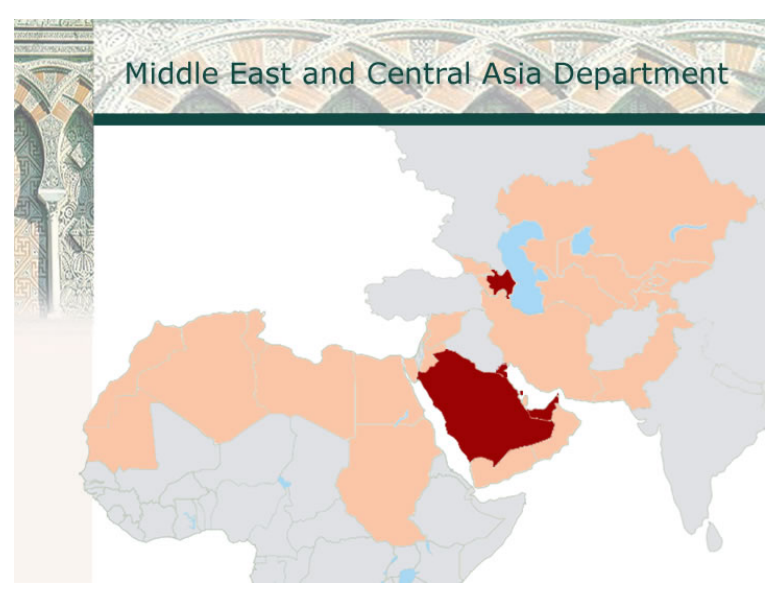

CU comprising five countries (Azerbaijan, Saudi Arabia, Kuwait, the U.A.E., and Bahrain)

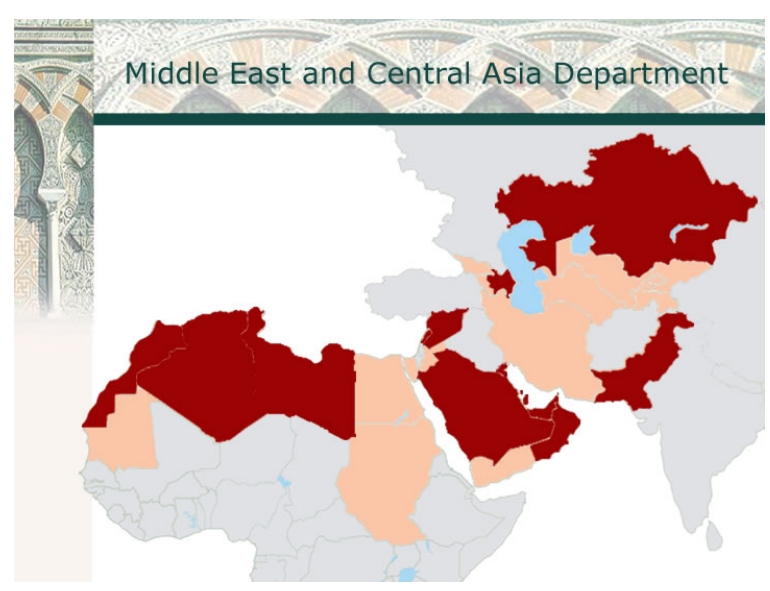

CU comprising 15 countries (Azerbaijan, Saudi Arabia, Kuwait, the U.A.E., Bahrain, Qatar, Oman, Pakistan, Algeria, Libya, Tunisia, Kazakhstan, Morocco, Lebanon, and Syria) 
Figure 4. Libya (SEED): Currency Maps

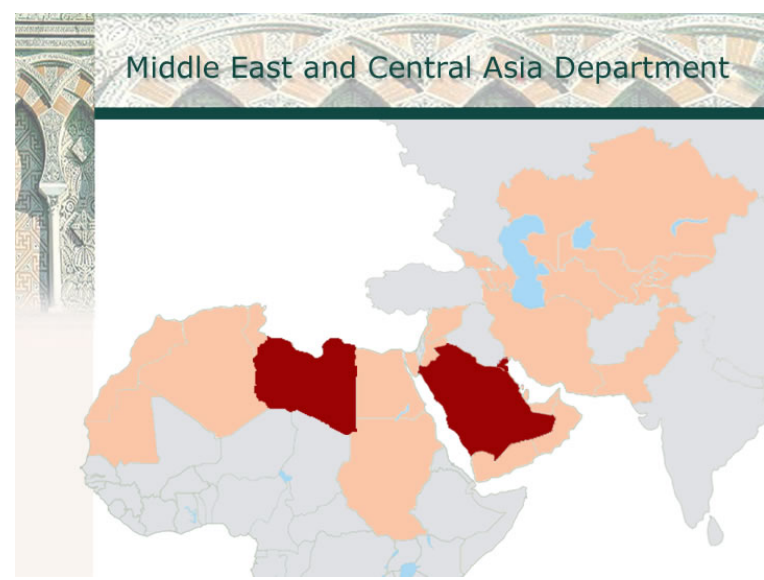

CU comprising three countries (Libya, Saudi Arabia, and Kuwait)

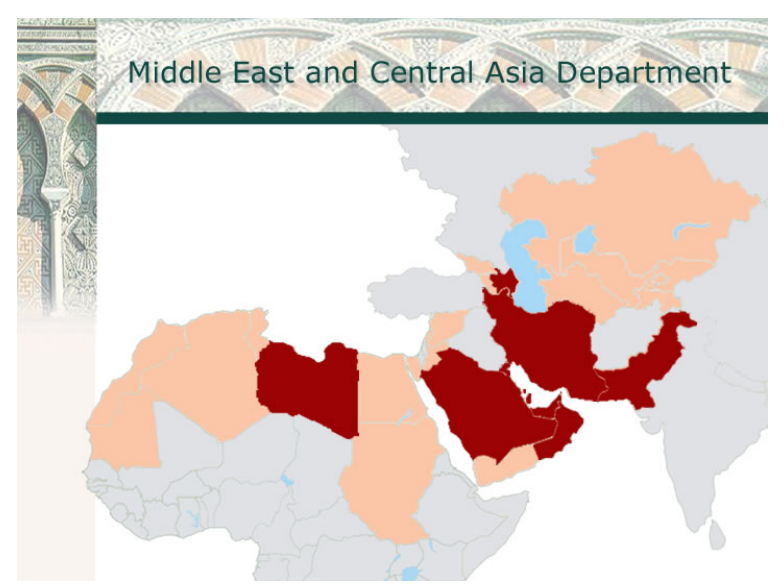

CU comprising 10 countries (Libya, Saudi Arabia Kuwait, the U.A.E., Qatar, Bahrain, Oman, Azerbaijan, Iran, and Pakistan)

Source: Authors' calculations.

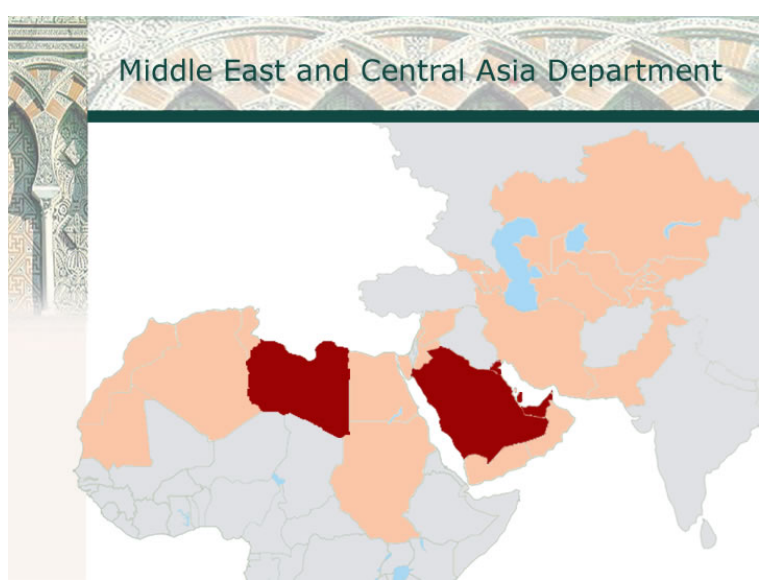

CU comprising five countries (Libya, Saudi Arabia, Kuwait, the U.A.E., and Qatar)

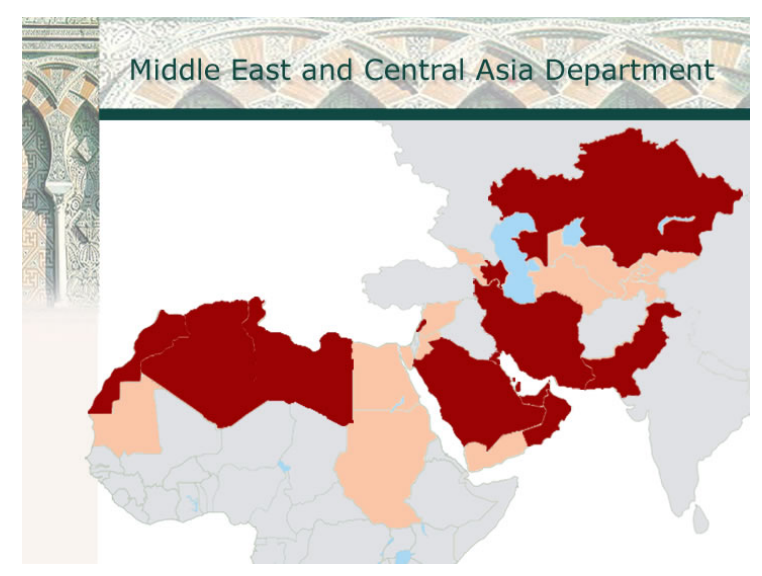

CU comprising 15 countries (Libya, Saudi Arabia Kuwait, the U.A.E., Qatar, Bahrain, Oman, Azerbaijan, Iran, Pakistan, Algeria, Tunisia, Kazakhstan, Morocco. and Lebanon) 


\section{References}

Alesina, Alberto, Robert J. Barro, and Silvana Tenreyro, 2002, “Optimal Currency Areas,” NBER Working Paper No. 9072 (Cambridge, Massachusetts: National Bureau of Economic Research).

Alesina, Alberto, and Robert J. Barro, 2002, “Currency Unions ,“ Quarterly Journal of Economics, Vol. 117, pp. 409-36.

Baxter, Marianne, and Michael A. Kouparitsas, 2006, "What Determines Bilateral Trade Flows?” NBER Working Paper No. 12188 (Cambridge, Massachusetts: National Bureau of Economic Research).

Bayoumi, Tamin, 1994, “A Formal Model of Optimal Currency Areas,” IMF Staff Papers, Vol. 41 (December), pp. 537-54.

Berengaut, Julian, and others, 1998, The Baltic Countries: From Economic Stabilization to EU Accession, IMF Occasional Paper No. 173 (Washington: International Monetary Fund).

Bottazzi, Laura, and Paolo Manasse, 2002, "Credibility and Seigniorage in a Common Currency Area,” Journal of Money, Credit, and Banking, Vol 34, No. 4 (November).

Ca’Zorzi M., R. de Santis, and F. Zampolli, 2005, "Welfare Implications of Joining a Currency Union,” ECB Working Paper No. 445 (Frankfurt: European Central Bank).

Chernookiy, Valery, 2005, “Adjustment to the Asymmetric Shocks and Currency Unions. The Case of Belarus and Russia,” Economics Education and Research Consortium Working Paper No. 05/07 (Moscow: Economics Education and Research Consortium Network).

Debrun, Xavier, Paul Masson, and Catherine Pattillo, 2002, "Monetary Union in West Africa: Who Might Gain, Who Might Lose, and Why,” IMF Working Paper 02/226 (Washington: International Monetary Fund).

Edwards, Sebastian, and I. Igal Magendzo, 2002, "Independent Currency Unions, Growth, and Inflation,” in Monetary and Economic Studies (special edition), December.

Edwards, Sebastian, 2006, “Monetary Unions, External Shocks and Economic Performance: A Latin American Perspective,” NBER Working Paper No. 12229 (Cambridge, Massachusetts: National Bureau of Economic Research).

Elborgh-Woytek, Katrin, 2003, “Of Openness and Distance: Trade Developments in the Commonwealth of Independent States, 1993-2002,” IMF Working Paper 03/207 (Washington: International Monetary Fund). 
Ferrero, Andrea, 2005, “Fiscal and Monetary Rules for a Currency Union, ECB Working Paper Series No. 502, July (Frankfurt: European Central Bank).

Frankel, Jeffrey A., and Andrew K. Rose, 2000, “Estimating the Effect of Currency Unions on Trade and Output,” NBER Working Paper No. 7857 (Cambridge, Massachusetts: National Bureau of Economic Research).

— 1996, “The Endogeneity of the Optimum Currency Area Criteria,” NBER Working Paper No. 5700 (Cambridge, Massachusetts: National Bureau of Economic Research).

Fryer, Roland G. Jr., and Paul Torelli, 2005, An Empirical Analysis of 'Acting White,' NBER Working Paper No. 11334 (Cambridge, Massachusetts: National Bureau of Economic Research).

Glick, Reuven, and Andrew K. Rose, 2002, "Does a Currency Union Affect Trade? The Time Series Evidence,” European Economic Review Vol. 46, No. 6, pp. 1125-51.

IMF, 2006, “Treatment of Currency Unions,” by Jean Galand and René Fiévet, STA, Fourth meeting of the Advisory Expert Group on National Accounts, January 30February 8, 2006, Frankfurt, SNA/M1.06/39.

Kenen, Peter B., 1969, “The Theory of Optimum Currency Areas: An Eclectic View,” in Monetary Problems of the International Economy, ed. by Robert A. Mundell and Alexander K. Swoboda (Chicago: University of Chicago Press).

Kirsanova, Tatiana, David Vines, and Simon Wren-Lewis, 2006, “Fiscal Policy and Macroeconomic Stability Within a CU,” CEPR Discussion Paper No. 5584 (London: Centre for Economic Policy Research).

Laabas, Belkacem, and Imed Limam, 2002, “Are GCC Countries Ready for Currency Union?” (Kuwait: Arab Planning Institute).

Masson, Paul, and Catherine Pattillo, 2004, “A Single Currency for Africa?,” Finance \& Development, December, pp. 8-15.

—, 2005, The Monetary Geography of Africa (Washington: Brookings Institution Press).

McKinnon, Ronald I., 1963, “Optimum Currency Areas,” American Economic Review, Vol. 53, September. 
Micco, Alejandro, Ernesto Stein, and Guillermo Ordoñez, 2002, “The Currency Union Effect on Trade: Early Evidence from the European Union” (Washington: Inter-American Development Bank).

Mundell, Robert A., 1961, “A Theory of Optimum Currency Areas,” American Economic Review, Vol. 51, September.

Mundell, Robert A., and Alexander K. Swoboda (eds.), 1969, Monetary Problems of the International Economy (Chicago: University of Chicago Press).

Nitsch, Volker, 2002, “Honey, I Shrunk the Currency Union Effect on Trade,” World Economy, Vol. 25, No. 4, pp. 457-74.

Nuti, D. Mario, 2002, “Costs and Benefits of Unilateral Euroization in Central Eastern Europe,” Economics of Transition, Vol. 10, No. 2, pp. 419-44.

Persson, T., 2001, “Currency Union and Trade: How Large Is the Treatment Effect?,” Economic Policy: A European Forum, No. 33, pp. 433-48.

Ricci, Luca Antonio, 1997, “A Model of an Optimum Currency Area,” IMF Working Paper 97/76 (Washington: International Monetary Fund).

Rose, Andrew K., and Charles Engel, 2002, “Currency Unions and International Integration,” Journal of Money Credit and Banking, Vol. 34, No. 3, August, Part 1.

Rose, Andrew K., and T. D. Stanley, 2005, "A Meta-Analysis of the Effect of Common Currencies on International Trade,” Journal of Economic Surveys, Vol. 19, No. 3, pp. 347-65.

Sánchez, Marcelo, 2005, “Is the Time Ripe for a Currency Union in Emerging East Asia? The Role of Monetary Stabilisation,” ECB Working Paper No. 567 (Frankfurt: European Central Bank).

Tsangarides, Charalambos G., and Mahvash S. Qureshi, 2006, “What is Fuzzy About Clustering in West Africa?,” IMF Working Paper 06/90 (Washington: International Monetary Fund).

Yehoue, Etienne B., 2005, “On the Pattern of Currency Blocs in Africa,” IMF Working Paper 05/45 (Washington: International Monetary Fund).

2004, “Currency Bloc Formation as a Dynamic Process Based on Trade Network Externalities,” IMF Working Paper 04/222 (Washington: International Monetary Fund). 